Virginia Commonwealth University VCU Scholars Compass

1987

\title{
Positivism: A Discredited Model of Science Still in Use in the Study and Practice of Management
}

Allen S. Lee

Virginia Commonwealth University, aslee@vcu.edu

Follow this and additional works at: http://scholarscompass.vcu.edu/info_pubs

Part of the Business Administration, Management, and Operations Commons, and the Management Information Systems Commons

(c) 2015 Allen S. Lee

\section{Downloaded from}

http://scholarscompass.vcu.edu/info_pubs/2

This Article is brought to you for free and open access by the Dept. of Information Systems at VCU Scholars Compass. It has been accepted for inclusion in Information Systems Publications by an authorized administrator of VCU Scholars Compass. For more information, please contact libcompass@vcu.edu. 


\title{
Positivism: A Discredited Model of Science Still in Use in the Study and Practice of Management
}

\author{
Allen S. Lee \\ September 1987 \\ (C) 2015 Allen S. Lee \\ allenslee@alum.mit.edu
}


Working Paper: 87-61

Positivism: A Discredited Model of Science Still in Use in the Study and Practice of Management

Allen S. Lee*

September 1987

*Assistant Professor of Management Science, Northeastern University.

The author has prepared this paper for presentation at the Joint National Meeting of the Operations Research Society of America and The Institute of Management Sciences (ORSA/TIMS), St. Louis, October 25-28, 1987. The author wishes to acknowledge the Cowan Research Fund for covering the publication costs of this working paper.

This paper may not be quoted or reproduced in whole or in part without the consent of the the author. Please forward comments and suggestions to the author. 


\begin{abstract}
This paper examines the positivist model of science and the reasons for which philosophers of science have abandonned it. However, despite its discredited status, positivism remains the espoused model of science in the study and practice of management. The paper will provide examples, identify the harmful consequences, and suggest alternative models.
\end{abstract}


An idea in good currency in the study and practice of management has been the idea of "science." As scholars of management, we call our journals Adminstrative Science Quarterly, Management Science, and Decision Sciences. As practitioners of management, we hire people who sell themselves as social scientists, management scientists, and computer scientists.

More than just an idea in good currency, "science" does offer real benefits to its users. The precise nature of the benefits depends, of course, on what we mean by "science," and how we put that meaning into practice.

At the same time, putting the wrong meaning of science into practice can do more harm than good. This paper's objective is to show that this is indeed the current situation. In the study and practice of management (and in other fields as well), the positivist model of science provides the definition of what we mean by "science." The problem is that the positivist model of science has long been discredited by the very same discipline -the philosophy of science -- which gave birth to it in the first place. Indeed, "[a]mong philosophers of science, no one wants any longer to be called a Positivist" (Schon: 1983, 48).1

However, even though the discrediting of positivism is a major development in its home field of philosophy, it is a development of which the field of management is largely unaware. Journal articles that report management research, for example, avow explicitly that they are applying positivist criteria. ${ }^{2}$ At the same time, in the management profession, the predominant epistemology of practice has been identified to be positivism (Schon, pp. 21-49). Moreover, scholarly observers of the 
methodologies which are in use in the study of management have, by and large, failed to point out that positivism has been abandonned by the very discipline which originated it; this even includes those observers who are opposed to positivism. ${ }^{3}$ Thus the current situation may be characterized as a classic case of the time lag experienced between the development of a technological innovation in one field and its adoption in another field. Valid models of science exist, but the discredited positivist model remains the one in use. In this context, the intended contribution of this paper is to be found in its attempt to expedite the diffusion of innovations from one field (the philosophy of science) to another field (the study and practice of management).

The author of this paper emphasizes that he is a supporter, not an opponent, of science. What the author opposes is not science, but one of the ways in which science has been observed and modeled. In opposing positivism, the author recognizes positivism as an account or a model of science, not science itself.

Different models of science, of course, offer different descriptions of how science proceeds. Of particular interest to this paper are the descriptions which the positivist model of science offers for each of the following: the role of observation in science, the role of logic in science, and the relationship of social science to natural science. As it turns out, philosophers and methodologists have shown the positivist model to be severely flawed in each of these areas.

The paper will now turn to an examination of these three 
aspects of the positivist model. After this examination, the paper will review the harmful consequences that follow from putting the positivist model into practice. The paper will end by briefly mentioning alternative models of science.

LESCRIBING THE ROLE OF OBSERVATION IN SCIENCE: POSITIVISM'S VERIFIABILITY CRITERION OF MEANING

What role does the positivist model of science set aside for observation? There are different ways to describe how science utilizes observation to determine whether or not a given theory is true. The description which the positivist model offers is contained in its "verifiability criterion of meaning," which maintains that "a statement is to be taken as meaningful only if it is capable of empirical verification" (Kaplan, 1964: 36). The verifiability criterion, moreover, specifies induction as the particular manner by which theory is to be grounded on observation.

Induction is the procedure by which a universal statement is said to be induced or generalized from statements of particulars. In science, this would involve the generalization of a scientific theory from a collection of individual statements of fact. In this view, the larger the collection of facts supporting a generalization, the greater the verification attributable to the generalization.

However, there is an unrectifiable difficulty that mars induction. It is that the induction itself is not empirically justifiable. Any attempt to establish the empirical validity of the concept of induction ultimately applies induction itself, thereby leading to an infinite regress in reasoning (Popper, 
1968a: 29, citing Hume). Moreover, there are counterinstances to the viability of induction as a method of science. When put into practice, induction allows the curious situation in which the investigator could seemingly verify a theory that is incorrect, simply by increasing the collection of observations that happen to be consistent with it. Popper identified this to be the practice of certain Marxists, Freudians, and Adlerians who, in the face of observations that plainly contradicted their respective theories, simply responded by gathering additional observations that were consistent with their theories. Through induction, they made their theories irrefutable (1968b: 35).4

Even the discipline of statistical inference has distanced itself from the notion of induction. Today, statisticians are careful to point out that the action of increasing a sample size does not increase the probability that a statistically inferred observation is true. Instead, increasing a sample size will have the effect of increasing what statisticians call the "level of confidence" which they may place in their sampling procedure. 5

Today, the recognized alternative to induction as a mode of empirical justification is deduction. A scientist's investigation, as described by the post-positivist philosophy of science, does not begin with observation, but with theory, the statements of which theorize the existence of unobservable entities. (Examples of theorized, unobservable entitities are protons, electrons, and photons in physics; double bonds, in chemistry; superstrings and black holes, in astronomy; and evolution, in biology.) In order to test these statements for what they theorize, the scientist applies them to a set of facts 
or "initial conditions" that describe, say, a concrete situation in a laboratory, from which a prediction or hypothesis is deduced. If what the theory predicts or hypothesizes to happen is subsequently observed to happen, then the original theorecical statements, and the existence of the unobservable entities to which they refer, would be considered confirmed, although the theoretical statements would remain open to disconfirmation by future, additional tests. Moreover, in this deductive procedure, the observation of even a single counterinstance would be sufficient to cast doubt on the theory as a true account of the subject matter, perhaps even to the point of falsifying it (Popper, 1968a, 1968b; Copi, 1982). For this reason, philosophers and methodologists today describe a theory not as verifiable, but instead, as falsifiable, refutable, testable, and disconfirmable. After all, given the problem with induction, no theory is verifiable; instead, a theory is, at best, only falsifiable. 6

The significance of the replacement of induction by deduction has not been fully recognized in the study of management. The generalizability of research findings, for example, continues to be a goal in management research, where it enjoys widespread recognition as the concept of "external validity," a term introduced by Campbell and stanley (1963).7 Another manifestation of induction is the lack of generalizability for which a case study is criticized. 8 (However, the message from philosophers and methodologists is that even the study of multiple cases would be unable to support a generalization.) Finally, textbooks on research methods in 
management still advocate the use of induction as a scientific method, and place induction on an equal footing with deduction. ${ }^{9}$

DESCRIBING THE ROLE OF LOGIC IN SCIENCE:

POSITIVISM'S AXIOMATIZATION OF SCIENTIFIC THEORIES

Whereas the role of observation concerns how to relate the statements of a scientific theory to an empirical subject matter, the role of logic concerns how to relate the statements of a scientific theory to one another. To describe the role of logic in science, positivism turns to the system of logic already developed for the axiomatic systems of mathematics, and then presents these "mathematical systems as the model for all systematic knowledge," including the empirical sciences (Hanson, 1969: 63). The importance of the "axiomatization of scientific theories" is that it is responsible for the emphasis which science, positivistically defined, places on mathematical analysis: "The logic of positivism is not merely a symbolic but a mathematical logic" (Kaplan, 1968: 391).10

In general, both inside and outside mathematics, axiomatic systems possess great esthetic appeal, and suggest themselves as a model of formal logic at its best.

The axiomatic method consists in accepting without proof certain propositions as axioms or postulates (e.g., the axiom that through two points just one straight line can be drawn), and then deriving from the axioms all other propositions of the system as theorems. The axioms constitute the 'foundations' of the system; the theorems are the 'superstructure,' and are obtained from the axioms with the exclusive help of principles of logic [Nagel \& Newman, 1960: 4-5].

The axiomatic systems of mathematics all exist independently of any empirical subject matter, but an axiomatic system may, of course, be subsequently interpreted to have empirical meaning. 
For example, Euclidean geometry, perhaps the best known example of an axiomatic system, makes reference to actual spaces.

Axiomatic systems are extremely attractive to science. The reason is that, if a theory were to be stated in the form of an axiomatic system, then the truth of the theory could be established simply by establishing the truth of the beginning axioms upon which the theory is built.

Therefore, the major benefit said to follow from describing a scientific theory as an axiomatic system is that "everything germane to comprehending such a system will be explicitly stated by the rules or also contained in the primitives and postulates [i.e., the beginning axioms]" (Hanson, 1969: 61). The practical consequence of this is that, as a theory is being formulated, any statement which cannot be shown to follow from the beginning axioms would be "exposed" as being groundless and "outside the system." Such a statement would be considered "metaphysical" or "subjective," and would therefore be stricken from the theory. Indeed, the suspected origin of such a statement would be the scientist's own values, opinions, and biases. Through the axiomatic logic of mathematics, the positivist model thus purges science of all human subjectivity and value judgments.

There is, however, a major, unrectifiable difficulty that emerges when fitting the theories of science to the axiomatic logic of mathematics. This difficulty follows from Godel's proof, which shows that axiomatic systems cannot be guaranteed to be either logically complete or free from logical inconsistencies. Godel's proof contradicts the positivist supposition that, in mathematics, all true statements in an 
axiomatic system can be shown to follow from the system's beginning axioms.

As an introduction to this issue, consider Euclidean geometry. No one has succeeded in proving the statement that "through a point outside a given line only one parallel to the line can be drawn"; indeed, it has been proven that it is impossible to derive this statement from Euclid's other axioms (Nagel \& Newman, 1960: 10). This is not an isolated example:

Mathematics abounds in general statements to which no exceptions have been found that thus far have thwarted all attempts at proof. A classical illustration is known as 'Goldbach's theorem,' which states that every even number is the sum of two primes. No even number has ever been found that is not the sum of two primes, yet no one has succeeded in finding a proof that Goldbach's conjecture applies without exception to all even numbers. Here, then, is an example of an arithmetical statement that may be true, but nonderivable from the axioms of arithmetic [Nagel \& Newman, p. 59].

Furthermore, the addition of axioms which would make a true statement, like Goldbach's theorem, derivable within this enlarged axiomatic system would not solve the problem. The reason is that, whenever this is attempted, there will always emerge a new set of true statements which, in turn, will not be derivable from the enlarged set of axioms. The mathematician Godel published the proof of this in 1931:

...he proved that is is impossible to establish the internal logical consistency of a very large class of deductive systems -- elementary arithmetic, for example -- unless one adopts principles of reasoning so complex that their internal consistency is as open to doubt as that of the systems themselves. In the light of these conclusions, no final systematization of many important areas of mathematics is attainable, and no absolutely impeccable guarantee can be given that many significant branches of mathematical thought are entirely free from internal contradiction [Nagel \& Newman, p. 6]. 
This situation presents the positivist model with a dilemma: should it accept, or reject, statements that are true, but are not derivable from the beginning axioms in an axiomatic system? This dilemma undermines positivism's effort of fitting the theories of science to the axiomatic logic of mathematics. On the one hand, the acceptance of true statements not derivable from beginning axioms would be an admission that the axiomatic systems of mathematics are unnecessary to the logic of science. On the other hand, the rejection of these statements, because they are "outside the system," would be invoking a logical standard that even axiomatic systems themselves cannot satisfy. Aside from Godel's proof, there are other major difficulties with the description of scientific theories as axiomatic systems. Briefly mentioned, they are the presumption that a theory, like axiomatic systems in general, can be developed independently of observation, that an observation can be made independently of theory, and that a completed theory and a completed observation are finally attached to each other through the positivist device of "correspondence rules" (Feigl, 1969: 15-17; Hanson, 1969: 5961; and Achinstein, 1969: 259-261). Today, philosophers of science take the position that observation guides theory, theory guides observation, and if correspondence rules exist, they exist in the positivist model of science, but not in science itself. 11 If not mathematical logic, then what logic might science turn to? First, it is important to remember that mathematics is a subset of formal logic, not vice versa. Scientists may avail themselves of the universe of rules comprising formal logic, not just the subset found in mathematics, when relating the 
statements of a scientific theory to one another. Second, it is important to remember that mathematics is one of the formal sciences; it is not one of the empirical sciences. As such, mathematics is not, and cannot be, the ideal discipline, so to speak, after which the empirical sciences are to model themselves. For these two reasons, the logic of science need not restrict itself to the logic of mathematics.

Mathematics, of course, may still find appropriate use in science. The point of Godel's proof is that putting the statements of a theory in mathematical form is not a sufficient condition for assuring that these statements can be logically related to one another. Moreover, putting the statements of a theory in mathematical form is not even a necessary condition for assuring logical consistency: there exist some systems of statements that satisfy the rules of formal logic, without being mathematical. 12

The study and practice of management have not yet acknowledged the significance of the difficulties that emerge when restricting the logic of scientific theories to the axiomatic logic of mathematics.

In the study of management, the positivist requirement that the logic of mathematics be adopted as the logic of science continues in full force. Two typical statements in this regard are made by Daft and stone. In his review article, "The Evolution of Organization Analysis in ASQ, 1959-1979," Daft observes: "The early articles were almost all qualitative, but the notion of a science gradually developed" (1980: 631). In his textbook on research methods in organizational behavior, Stone 
writes (1978: 35$)$ :

In order to empirically investigate the credibility of [a] hypothesis you have to do several things, including... performing statistical analyses of the data...

As should be obvious, the measurement of variables is critical in any empirical study. If variables cannot be operationally defined and measured, hypotheses involving such variables can never be empirically tested. Simply put, measurement is the sine qua non of all empirical research.

A dramatic example of the extent to which the study of management is still actively attempting to fit its theories to the axiomatic logic of mathematics is a 1982 Administrative Science Quarterly article by Bagozzi and Phillips. This 1982 article presents, in detail, a new methodology which it calls the "holistic construal," the purpose of which is to provide a major advance in "construct validation" in organizational research. The two authors explain that the origins of the new methodology which they are offering "lie in conceptualizations of theoretical systems proposed by philosophers of science" (p. 461). However, the philosopher whom they quote is the positivist philosopher Hempel, and they base their new methdology on the axiomatic system which Hempel outlined in a book that he published in 1952 -- a book whose axiomatic views of scientific theories were already seriously weakened, if not totally abandonned, by positivists themselves in the $1960^{\prime} \mathrm{s}$. By that time, Hempel was no longer a positivist (Hanson, 1969: 84). The two authors, in their $\underline{A S Q}$ article, describe in great detail their adaptation of Hempel's axiomatic system, complete with correspondence rules. The two authors even make the explicit assertion that their new methodology contains positivist features (p. 460). It is doubtful that this assertion would have been made (or the article 
even published) if the authors, the reviewers, or the editors had been aware of the recent developments in the philosophy of science.

The positivist insistence on the logic of mathematics is also clearly evident in the practice of management. For example, in the profession of management science/operations research, mathematics is seen as a necessary ingredient in science. In his discussion of the historical development of operations research, Ackoff observes: "OR came to be identified with the use of mathematical models and algorithms... This obsession with techniques... had three major effects on the practice of or..." (1979: 94). (None of these effects, Ackoff goes on to explain, were desirable.) Similarly, textbooks for operations research and management science define these fields in terms of mathematics; for example, in his widely used textbook, Wagner explicity defines operations research as a science, and specifies that an OR approach to a problem must include a formal mathematical model (1969: 6). Finally, an article in Interfaces, a journal dedicated to the implementation of operations research and management science, provides a similar definition: "Operationally defined, operations research (OR) consists of a class of mathematical/statistical research techniques which have come to be utilized for solving problems likely to arise within organizations" (Lonnstedt, 1975, cited by Mintzberg, 1979: 149). Thus, despite the unrectifiable difficulties associated with describing science as if it were, or could be, like the axiomatic systems of mathematics, the study and practice of management both continue to perpetuate the discredited positivist notion that 
mathematical analysis is necessary to reasoning in science.

DESCRIBING THE RELATIONSHIP OF SOCIAL SCIENCE TO NATURAL SCIENCE: POSITIVISM'S THESIS OF THE UNITY OF SCIENCE

To describe the relationship of social science to natural science, the positivist model of science offers its "thesis of the unity of science," which is actually three theses in one: the unity of language, the unity of laws, and the unity of method (Hempel, 1969).

The unity of language maintains that all scientific discourse, including social science, may be expressed in the same language (really, the language of natural science), which would refer only to the observable properties of physical entities.

The unity of laws maintains that the subject matters of interest to social science are ultimately explainable by physical laws (namely, the laws of natural science).

Last, and most important, the unity of method maintains that the methods of natural science are the ideal after which the methods of social science are to model themselves (Kolakowski, 1968: 178).

It is one thing to describe, in principle, the unity of science. It is quite another thing to describe, in detail, how the unity actually exists or can be implemented. As it turns out, positivist philosophers themselves have failed in their attempts to work out the details. Hempel, in a 1969 article, gives an account of the many changes that the thesis of the unity of science had undergone in attempts by such positivists as Neurath, Carnap, and Feigl to implement it. The result, Hempel concludes, is that the later versions of the thesis "have yielded 
formulations that have been increasingly cautious, elusive, and weak" (1969: 190).

In the post-positivist philosophy of science, one position that is emerging actually turns the tables on the positivist position. It is the position that the methods of natural science are to be regarded, at best, as a subset of the methods, rather than the only set of methods, that may be considered for use in social science. Elements of this position can be seen in the work of Nagel and Schutz.

Nagel (1979: 450-453) takes issue with the position which holds that the controlled laboratory experiments of natural science are the ideal form of experimentation, and that other kinds of experiments are only second-best alternatives. (The other kinds of experiments include statistical experiments and natural experiments, which are commonly used in social science.) Nagel observes that, far from being the ideal, the controlled laboratory experiments of natural science are actually a limiting case in a larger category of methods that he calls "controlled empirical inquiry." In controlled empirical inquiry, certain factors vary while other factors remain constant, so as to allow the scientist to test for the existence of relationships theorized to exist among the different factors. It is irrelevant, Nagel points out, whether the scientist enjoys the convenience of being able to impose, at will, the desired variations and constancies (as in a laboratory setting), or suffers the inconvenience of being a passive observer who must search for the desired variations and constancies where they occur naturally (as in a natural experiment, or even in a 
statistical experiment involving Census data). Social science may therefore legitimately avail itself of the full range of methods found in the larger category of "controlled empirical inquiry," rather than restrict itself to the limiting subset (i.e., controlled laboratory experiments) said to be the ideal in natural science.

Schutz (1973) observes that social science deals with what he calls "prescientific" constructs as well as scientific constructs. Prescientific constructs refer to the everyday thinking and common-sense knowledge of the people whom the social scientist is observing. As such, prescientific constructs refer to the social reality that the observed people themselves have created, and to the meaning that this reality has for them (rather than for the scientific observer). Prescientific constructs are therefore a component of the empirical subject matter confronting the social scientist; they are among the "data" for the social scientist to observe and consider. Then, in order to provide an explanation of the subject matter of interest, the social scientist formulates a system of scientific constructs, which, like the scientific constructs in natural science, are a system of formal statements. The so-called methods of natural science, if they are to be considered for use at all in social science, would therefore become relevant at the level of the scientific constructs. At the same time, this means that the prescientific constructs, which have no counterpart in natural science, would call for methods of investigation that simply do not exist in natural science. (Today, the postpositivist philosophy of science recognizes these as the methods 
of hermeneutics, phenomenology, ethnomethodology, and so forth.)

Therefore, in Schutz's framework, as in Nagel's, we may conclude that the methods of natural science merely comprise a subset of the methods, rather than the only set of methods, for use in social science.

Despite these developments in the philosophy of science, the study and practice of management have kept alive the positivist thesis that the methods of social science are to modeled after the methods of natural science.

In the Academy of Management Review, Daft writes (1983: 539; emphasis supplied):

What research techniques can be used to obtain significant new knowledge about organizations? Many of us would respond by referring to what has become known as the natural science model of research... In organizational textbooks... the natural science model typically is associated with good research...

Susman and Evered, in their Administrative Science Quarterly article, write (1978: 582-583):

...organizational researchers have taken the positivist model of science, which has had great heuristic value for the physical and biological sciences... and have adopted it as the ultimate model of what is best for organizational science.

In another Administrative Science Quarterly article, Dunbar (1983) writes about the influence of the famous organizational theorist, James D. Thompson. In one of Thompson's essays, published in ASQ in 1956, Thompson did not merely suggest the utilization of natural-science methods, but referred to them as the model for research methods in administrative science. ${ }^{13}$ Dunbar, in his 1983 article, also raises the issue of the difference between the presumption of "objective" phenomena and the presumption of "subjective" phenomena. The issue is 
important because the objectivity of phenomena is a positivist concept. 14 Dunbar reports that the majority of studies in Administrative Science Quarterly and Harvard Business Review have taken the view that administrative behaviors are objective phenomena, as opposed to subjective phenomena.

In the practice of management, the field of management science/operations research provides a sharp illustration of the primacy ascribed to the methods of natural science. In their textbook, Management Science, Lee, More, and Taylor state (1985: 5; emphasis supplied):

...management science includes a carefullly constructed methodology for analysis. This methodology has been adapted from the natural sciences and is termed the scientific method.

HARMFUL CONSEQUENCES OF THE POSITIVIST MODEL OF SCIENCE

Developing a model that is oversimplied or otherwise incorrect is not, in itself, harmful. After all, a model is never an exact replica of the subject matter that it is a model of. The criteria by which to judge a model, therefore, include the intentions of the modeler.

Judging by these intentions, the positivist model of science can actually be defended. Feigl, one of the original proponents of positivism, stated in 1970 that the positivist model was only intended to be a highly artificial reconstruction of scientific practice, not a prescription for how scientific researchers themselves ought to proceed in constructing scientific theories (p. 13):

It should be stressed, not bashfully admitted, that the rational reconstruction of theories [as existing in the 
orthodox positivist view] is a highly artificial hindsight operation which has little to do with the work of the creative scientist. No philosopher of science in his right mind considers this sort of analysis as a recipe for the construction of theories...

Certainly by 1970, therefore, philosophers of science who had originally developed the positivist model were no longer prescribing it as the way in which science ought to be done, if indeed they had ever prescribed this at all. The value of the positivist model is to be found, therefore, not as a prescription, but as a way of clarifying the logical and empirical aspects of how a scientific theory works. 15

By way of analogy, consider the relationship between a map and a territory. Making a map conform to a territory is a reasonable endeavor. A map that conforms to a territory can clarify, for the traveler, different features in the territory of interest. However, doing the reverse -- making a territory conform to a map -- is a questionable endeavor. Making the actual practice of science conform to the positivist model of science is, in the same way, a questionable endeavor -- an endeavor which the study and practice of management have been actively pursuing. 16 In doing so, they have been attempting to do what, according to Feigl, no philosopher in his right mind would consider. This paper identifies three harmful consequences the follow from imposing the positivist model as the way that science ought to be done in the study and practice of management. The first harmful consequence of putting the positivist model into practice is that it precludes or discourages the utilization of methods that would be beneficial to the study and practice of management. 
For example, the verifiability criterion of meaning excludes case studies. The emphasis that the verifiability criterion places on induction and generalizability has had the effect of withilolding recognition for the methodological validity of case studies. However, when removed from the discredited inductive framework and placed instead in a deductive framework, case studies become altogether scientific. The study of a single case is perfectly suited to turning up the single counterinstance needed to falsify a theory.

For another example, the thesis of the unity of science excludes the methods needed to investigate "prescientific" constructs, which (as mentioned above) refer to the social reality that everyday people themselves create and the meaning that this reality has for them (rather than for the scientific observer). The thesis of the unity of science recognizes natural science as the model for social science. However, "prescientific" constructs have no counterpart in the strictly physical reality of nature. Natural science, if taken as the model for social science, would therefore have no methods to offer for the investigation of prescientific constructs. Indeed, methods which have proven useful for investigating prescientific constructs, such as ethnographic methods, would then be dismissed as unscientific, since they do not fit into the scheme of the natural-science model. Denied the needed methods, the study and practice of management would be unable to develop a satistfactory understanding of such crucial phenomena as leadership and organizational culture.

The second harmful consequence of putting the positivist 
model into practice is that it has the effect of fitting the subject matter to the needs of mathematical logic, rather than fitting the most appropriate logic -- mathematical or otherwise -- to the needs of the subject matter.

In the practice of management, the profession of management science/operations research provides an excellent illustration of this. According to Ackoff (1979: 94):

...OR came to be identified with the use of mathematical models and algorithms rather than the ability to formulate management problems, solve them, and implement and maintain their solutions in turbulent environments.

-..practitioners decreasingly took problematic situations as they came, but increasingly sought, selected, and distorted them so that favoured techniques could be applied to them. This reduced the usefulness of $O R$, a reduction that was well recognized by executives who pushed it further and further down in their organizations, to where such relatively simple problems arose as permitted the application of OR's mathematically sophisticated but contextually naive techniques.

Ackoff mentions two additional, related problems that follow from the OR profession's identification with mathematics (pp. 94-95). One is that the mathematical techniques of $O R$ "can be easily taught by those who do not know where, when and how to use them" (p. 94). The other problem that follows from the profession's emphasis on mathematics "is that those who either practise or preach it have come to be more and more like each other" (p. 95), thereby having the ironic effect of homogenizing a profession which originally proclaimed its interdisciplinary approach as a distinguishing strength.

In the study of management, the positivist practice of fitting the subject matter to the needs of mathematical logic is seen in two dramatic examples that the paper has already 
mentioned: the 1982 ASQ article by Bagozzi and Phillips, which applies positivism as it existed in 1952, and the textbook by Stone, in which he asserts that "measurement is the sine qua non of all empirical research." However, the emphasis on the logic of mathematics, to the exclusion of other forms of logic, is misplaced, given that Godel's proof has demonstrated that the logical completeness and logical consistency of axiomatic systems cannot always be guaranteed, and therefore cannot be assumed. Moreover, the exclusionary emphasis on mathematics, which the positivist model requires, also has the harmful effect of ruling out the utilization of qualitative methods, without which, unfortunately, prescientific constructs would be left uninvestigated.

The third harmful consequence of the positivist model of science pertains to the practice of management. Value judgments -- an indispensable resource in management practice -- are minimized, or denied a methodological role altogether, when management practice is made to fit the positivist model.

Even if the positivist model were flawless, its originators had intended it only to be an epistemology of research in science, not an epistemology of practice in the professions.

Both science and the positivist model of science are concerned with knowledge as diagnosis -- that is, knowledge as a truthful representation of nature and society in the way that they exist. In the endeavor of science, the value judgments of the scientist are often seen (whether correctly or incorrectly) as hindrances to the attainment of objective knowledge. Scientific procedures, especially in the viewpoint of positivism, 
therefore serve to eliminate or control the role of value judgments.

In contrast to science, the professions (including management) are concerned not just with knowledge as diagnosis, but also with knowledge as prescription -- that is, knowledge as an effective design for changing things into the way they ought to be. In the endeavor of design, the value judgments of the professional are not a hindrance to be eliminated, but are an indispensable resource for identifying the way things ought to be. Value judgments play a key role in this effort. However, because the positivist model of science is concerned with knowledge as diagnosis, not as prescription, the imposition of the positivist model on the management profession has had the consequence of diminishing, or eliminating entirely, the role of value judgments. Along these lines, Ackoff writes (1979: 103):

Objectivity is not the absence of value judgments in purposeful behaviour... That which is true works, and it works whatever the values of those who put it to work. It is value-full, not value free.

The positivist model of science -- with its verifiability criterion of meaning, its axiomatization of scientific theories, and its thesis of the unity of science -- is not equipped, and was never intended to be equipped, to handle the "value-full" aspects of professional practice, whether in management or any other profession.

\section{ALTERNATIVE MODELS OF SCIENCE}

The paper has already mentioned some alternative models of science, such as Popper's deductive model for testing theories, and the model that emerges from the work of Nagel and Schutz, in 
which the methods of natural science are neither exalted nor denied, but are portrayed as only a subset of the methods appropriate for use in social science. The paper will conclude by continuing these brief mentions of alternative, non-positivist models of science.

Among these models, hermeneutics and phenomenology deserve mention.

Hermeneutics originated as the study and interpretation of the literary and religious texts. The motivating question in hermeneuitics is: once certain thoughts and meanings ("prescientific constructs") have been recorded in the form of a text, how may readers of the text, who belong to a different time and culture from the writers of the text, proceed to interpret the text for its original meaning, where other portions of the text itself are the primary, or sometimes the only, crossreferencing tools available? Today, the methods of hermeneutical interpretation not only are applied to texts, but also are extended to observable human actions, which are framed as "text analogues." (See Tice and Slavens, 1983: 293-299; Taylor, 1979: 25-71; and Bernstein, 1978, 1983).

Phenomenology originated in philosophy, but quickly found application by social scientists who viewed positivism as incorrect or incomplete. Phenomenology works from the perspective of the individual, and inquires into the elementary structures of the individual's everyday experience. Phenomenology's subject matter is the consciousness and the meaning with which the individual approaches his or her world, and its purpose is the explanation of how this consciousness and 
meaning arise in everyday experience. As such, phenomenology is useful not only for studying the everyday experience of individuals, but also for clarifying the everyday experience of social scicatists themselves in their research activity. In this special sense, phenomenology makes the claim of being a discipline that is "self-founding" -- unlike either natural science or the positivist model of science, both of which, in the phenomenological framework, have been criticized for failing to examine the phenomenology of the observing scientist.

Phenomenology, in its home field of philosophy, is so highly technical as to be incomprehensible to non-philosophers. Fortunately, some social scientists have already taken it upon themselves to adapt phenomenology into more readily accessible forms. In sociology and anthropology (and, to an increasing extent, in organizational studies), the phenomenological approach appears in ethnography, ethnomethodology, and participantobservation. These forms are overlapping and often indistinguishable. Each one, moreover, can be subdivided into its own schools of thought. For example, Sanday (1979) divides ethnography into the holistic, semiotic, and behavioristic schools of thought, and she further subdivides the semiotic school into ethnoscience and thick description. (See also Luckmann, 1978a, 1978b; and Garfinkel, 1967).

Hermeneutics and phenomenology are only presented as examples of established methodologies for investigating prescientific constructs. There is no reason that the management researcher or practitioner must adhere to these established methodologies, just as long as the prescientific constructs are 
examined, rather than being ignored by a preoccupation with the scientific constructs.

This discussion suggests a complementary relationship between the methods needed at the prescientific level of study and the methods needed at the scientific level of study. As it turns out, the author of this paper has identified four organizational case studies, published in the management literature, which exhibit this complementary relationship (Lee, 1985, 1986a, 1986b, 1987). Each of the case studies demonstrates how the examination of prescientific constructs can and does take place side-by-side with the examination of scientific constructs. The examination of subjective human meaning at the prescientific level in no way contradicts, precludes, or is precluded by, the examination of formal variables and relationships (mathematical or otherwise) at the scientific level. Incidentally, even though each one is the study of a single case, each one also demonstrates the ease with which the the truth of scientific constructs can be tested by Popper's deductive logic, whether with qualitative observations or quantitative observations.

It is beyond the scope of this paper to give a full, or even an adequate, account of non-positivist models of science. Such accounts may be found in the works of Bernstein $(1976,1983)$, Burrell and Morgan (1979), Kuhn (1962, 1977), Nagel (1979), Popper (1968a, 1968b), Schon (1983), Schutz (1973), and Simon (1981), as well as in the collections edited by Lakatos and Musgrave (1970), Natanson (1963), Luckmann (1978c), Rabinow and Sullivan (1979) and Van Maanen (1979).

Despite the need for an adequate model of science in the 
study and practice of management, such a model is not likely to appear soon. The philosophy of science has not yet reached a consensus on a model of science for natural science. It is unlikely that an adequate model of science for management will be developed any sooner. 
NOTES

${ }^{1}$ Schon quotes Bernstein (1978: 207): "There is not a single major thesis advanced by either ninetheenth-century Positivists or the Vienna Circle that has not been devastatingly criticized when measured by the Positivists' own standards for philosophical argument. The original formulations of the analytic-synthetic dichotomy and the verifiability criterion of meaning have been abandonned. It has been effectvely shown that the Positivists' understanding of the natural sciences and the formal disciplines is grossly oversimplified. Whatever one's final judgment about the current disputes in the post-empiricist philosophy and history of science...there is rational agreement about the inadequacy of the original positivist understanding of science, knowledge and meaning."

${ }^{2}$ Sabatier (1978: 397) writes in Administrative Science Quarterly: "...as used in this paper, 'technical information' refers to empirical information... [T]his definition does maintain the traditional positivist distinction between empirical information and normative preferences."

Bagozzi and Phillips (1982: 460) write in Administrative Science Quarterly: "The procedures [being recommended] share some features of the positivist, realist, and instrumental approaches..."

${ }^{3}$ See Susman and Evered (1978), and also Burrel and Morgan (1979) 。

${ }^{4} \mathrm{~A}$ second unrectifiable difficulty marring induction is that, even if the validity of induction could be established, it 
would still be impossible to generalize scientific theories from individual statements of fact. To understand this, first consider the difference between theoretical statements and observation statements. Theoretical statements "concern unobservable entities, such as molecules and atoms, electrons and protons, and the like" (Copi, 1982: 466). In contrast to theoretical statements, observation statements refer to directly observable entities. The difficulty that arises for induction is that, because the statements of scientific theories refer to unobservable entities, these statements "cannot be logically reduced to elementary statements of experience" (Popper, 1968a: 36). In other words, there are no observation statements from which we could induce or generalize a theoretical statement. For example, what would be the observation statements from which we could induce or generalize the theoretical statement, "atoms exist"? The theorized existence of unobservable entities may, of course, be demonstrated, but not through induction. Thus, a strict adherence to induction would have the effect of eliminating the theories of science. In this context, Popper states (p. 36): "positivists, in their anxiety to annihilate metaphysics, annihilate natural science along with it."

${ }^{5}$ of course, in statistical inference, a large sample size is properly regarded as useful. As such, the recognition given to the valid role of a large sample size -- the role of a large number of observations of particulars -- could also be argued to be recognition of the validity of induction. This would lead to the conclusion that the entire field of statistical inference employs the discredited notion of induction. However, 
statisticians are quick to indicate otherwise. In statistical inference, a large sample size supports a high "level of confidence" for a given observation statement (such as "the mean income for all people in the population is between $\$ 10,000$ and $\$ 12,000 ")$. However, in supporting a high level of confidence, a large sample size is not supporting the truth of the observation statement.

Consider the statistical meaning of a $95 \%$ confidence level associated with a sample consisting of 100 observations. As statistics textbooks painstakingly explain (and as sophomores painstakingly ignore), a $95 \%$ confidence level means the following: if the observer were to repeat the experiment of taking a sample of 100 observations from the population many times, then the observation statement resulting from the sample ("the mean income for all people in the population is between $\$ X$ and $\left.\$ Y^{\prime \prime}\right)$ would be expected to be true for every 95 experiments out of 100. This is quite different from asserting that the probability of such an observation statement's being true is 958 . Indeed, the correct interpretation is that this probability is either 1 or 0 : the observation statement (that "the mean income for all people in the population is between $\$ X$ and $\$ Y^{\prime \prime}$ ) is either true or false. Therefore, according to standard statistical theory, a large sample size does not provide support for the truth of an observation statement, but provides support for the level of confidence that an observer can place in his or her sampling procedure.

The concept of sample size (whether large or small) becomes relevant and takes on validity only if the scientist is deriving 
an observation statement by inference through a sample. Since there are also other ways of deriving observation statements -such as direct observation in a laboratory experiment or a natural experiment -- a large sample size is therefore not a necessary condition in scientific observation. Conversely, this also means that an across-the-board fiat which requires large sample sizes in all observational situations is unnecessary. To the extent that this fiat follows from a belief in the validity of induction, it is incorrect.

To claim otherwise -- to claim that a large sample size provides support for the truth of an observation statement -would be presuming the validity of induction.

Another point that follows from the above discussion is that the utility of a large sample size is restricted to the specific role of bringing about a high "confidence level" for a particular observation statement (such as, "the mean income of all the people in the population falls between $\$ 10,000$ and $\$ 12,000 ")$, not a theoretical statement. (As already mentioned, it is only possible to derive an observation statement, not a theoretical statement, from other observation statements.) In the deductive testing of theories, this observation statement can then be compared to what the theoretical statements predict or hypothesize to happen.

${ }^{6}$ Moreover, as mentioned in one of the previous footnotes, even if induction could be established as a legitimate method of empirical proof, it would still only allow the scientist to derive statements about observable entities, not unobservable entities; thus a strict adherence to induction would preclude the 
formulation of most scientifics theories, since most scientific theories refer to unobservable entities.

7 In his 1985 Academy of Management Review article, Mitchell writes (p. 194): "External validity (Cook \& Campbell, 1976; Campbell \& Stanley, 1963) reflects the extent to which the inference drawn from any particular experiment can be generalized to or across times, settings, and persons." Mitchell then suggests two ways by which to achieve this.

In their 1986 Academy of Management Review article, Venkatraman and Grant state the following about "construct measurement" (p. 72): "In one sense it is concerned with the generalizability of results..." Correct construct measurement, they argue, leads to generalizability.

${ }^{8}$ In her 1983 Academy of Management Review article, Harrigan writes (p. 398): "In much existing research, insights gained using 'fine-grained' (Hambrick, 1981) methodologies (such as case studies) lack generalizability..."

${ }^{9}$ In his textbook, Research Methods in Organizational

Behavior (1978), Stone devotes a footnote to the current philosophical misgivings about induction (p. 9), but still places induction on an equal footing with deduction as one of the components of scientific method (p. 8). Stone also writes ( $p$. 9): "Having a set of facts that the scientist believes to be probably true, he or she then uses induction (i.e., a process of moving from specifics to generalizations) to develop explanations of such facts."

${ }^{10}$ Another benefit is that, with an axiomatic system, "we can mathematically extract unexpected consequences that [are] 
logically 'contained in' [the beginning axioms and transformation rules]... Thus [the positivist philosopher] Hempel spoke of mathematics as a 'logical juice extractor'" (Barker, 1969: 238). Thus an axiomatic system woula, in this instance, surface any empirical content that a scientist did not originally intend to be his or her theory -- not only those which would turn out to be false, but those which would turn out to be true.

11 "The fact is that no human perception is immaculate [i.e., free from theoryl, certainly no perception of any significance for science. Observation is already cognition, not just material for subsequent knowledge..." (Kaplan, 1964: 131).

"Nothing is first known through the senses. We start with conjectures, interpreted data; there is no such thing as passive experience" (Tice and Slavens, 1983: 200-201, characterizing Popper's position).

"...it is now theory... that determines the meaning and acceptability of observation, rather than vice versa" (Shapere, 1969: 130).

"...'facts' are determined by the theories and methods that generate their collection; indeed, theories and methods create the facts" (Ratcliffe, 1983: 148).

"To put my position more generally, if you extract the physical interpretation from a physical theory, the result will not be physics, but algebra, pure and simple. What then is the interpretation-free [i.e., observation-free] theory within, for example, contemporary microphysics? It is little more than a motley combination of classical matrix algebra, non-commutative operator calculus, and sundry mathematical inelegancies that 
never would have been introduced into the algorithm of quantum electrodynamics had they been in any way avoidable" (Hanson, $1969: 75)$.

${ }^{12}$ One example is Darwin's theory of evolution -- the statements of which are altogether logically consistent with one another, even though they are presented in the form of English sentences, rather than the form of mathematics. Another example is the standard syllogism ("All men are mortal," "Socrates is a man," "Socrates is mortal"), which is considered a a paradigm of formal logic.

13 "Thompson [in 1956] assumed that administrative behavior was characterized by identifiable regularities and that an administrative science should focus on identifying these regularities... In making repeated analogies to the physical and biological sciences, he implied that administrative behaviors are objective phenomena and that the research methods used by natural scientists to make empirical generalizations are appropriate for administrative research...

"Twenty-five years after Thompson's essay, many administrative scientists continue to utilize natural science methods..." (Dunbar, 1983: 129)

${ }^{14}$ originating in the positivist description of how natural science proceeds, the objectivity of phenomena is the presumption that phenomena have an existence independent of knowing human subjects, particularly the observing scientist. Part of the presumption is that the behavior of objective phenomena is governed by "laws," which are "out there," in the phenomena itself, waiting to be discovered by the scientist with the help 
of mathematical theories, quantitative data, and experimental procedures (Schon, Drake \& Miller, 1984: 9; Burrell \& Morgan, 1979: 4). Positivism, in describing natural science as the model for social science to follow, carries over the presumption of objective phenomena to the study of social reality. Contrary to the positivist concept of objective phenomena is the postpositivist description of social phenomena as "subjective," in that their existence is explicitly said to be inseparable from knowing human subjects, both those who are being observed and those who are doing the observing.

15"... wish to say that the 'orthodox' view of scientific theories can help in clarifying their logico-mathematical structure, as well as their empirical confirmation (or disconfirmation)" (Feigl, 1970: 13).

"The value of the seemingly very artificial logical reconstruction consists in the distinction that it allows us to make between logicomathematical and empirical questions that may be asked regarding scientific theories" (Feigl, 1969: 17).

${ }^{16}$ For another analogy, consider the relationship of the rules of grammar to the actual cognitive processes by which people speak. The rules of grammar are only an artificial, logical reconstruction of the actual ways in which people put together phrases and sentences. As such, the rules of grammar can certainly help to clarify, both for native speakers and for linguistic observers, the structure of the language being spoken. However, adapting Feigl's terminology, we might say that no person in his or her right mind considers the rules of grammar to embody the actual creative process by which people produce 
speech. In the same way, the positivist model of science can help to clarify, both for scientists and for philosophers observing them, the structure of the science being practiced, even if the positivist model does not embody the actual creative process by which scientists produce theories. 


\section{REFERENCES}

Achinstein, P. (1969) "Approaches to the Philosophy of Science." In P. Achinstein \& S. Barker, The Legacy of Logical Positivism: 259-291. Baltimore: Johns Hopkins.

Barker, S. (1969) "Logical Positivism and the Philosophy of Mathematics." In P. Achinstein \& S. Barker, The .uegacy of Logical Positivism: 229-257. Baltimore: Johns Hopkins.

Ackoff, R. (1979) "The Future of Operational Research Is Past." Journal of the Operational Research Society, 30: 93-104.

Bagozzi, R., \& Phillips, L. (1982) "Representing and Testing Organizational Theories: A Holistic Construal." Administrative Science Quarterly, 27: 459-489.

Bernstein, R. (1983) Beyond Objectivism and Relativism: Science, Hermeneutics, and Praxis. Philadelphia: University of Pennsylvania Press.

Bernstein, R. (1978) The Restructuring of Social and Political Theory. Philadelphia: University of Pennsylvania Press.

Burrell, G., \& Morgan, G. (1979) Sociological Paradigms and Organisational Analysis. London: Heinemann.

Campbel1, D. \& Stanley, J. (1963) Experimental and QuasiExperimental Designs for Research. Boston: Houghton Mifflin.

Copi, I. (1982) Introduction to Logic. New York: Macmillan.

Daft, R. (1983) "Learning the Craft of Organizational Research." Academy of Management Review, 8: 539-546.

Daft, R. (1980) "The Evolution of Organization Analysis in ASQ." Administrative Science Quarterly, 25: 623-636.

Dunbar, R. (1983) "Toward an Applied Administrative Science." Administrative Science Quarterly, 28: 129-144.

Feigl, H. (1969) "The Origin and Spirit of Logical Positivism." In P. Achinstein \& S. Barker, The Legacy of Logical Positivism: 3-24. Baltimore: Johns Hopkins.

Garfinkel, H. (1967) Studies in Ethnomethodology. Englewood Cliffs, New Jersey: Prentice-Hall.

Hanson, N. (1968) "Logical Positivism and the Interpretation of Scientific Theories." In P. Achinstein \& S. Barker, The Legacy of Logical Positivism: 57-84. Baltimore: Johns Hopkins. 
Harrigan, K. (1983) "Research Methodologies for Contigency Approaches to Business Strategy." Academy of Management Review, 8: 398-405.

Hempel, C. (1969) "Logical Positivism and the Social Sciences." In P. Achinstein \& S. Barker, The Legacy of Logical Positivism: 163-194. Baltimore: 'Tohns Hopkins.

Kaplan, A. (1964) The Conduct of Inquiry. New York: Chandler.

Kolakowski, L. (1968) The Alienation of Reason: A History of Positivist Thought. Garden City, New York: Doubleday.

Kuhn, T. (1962) The Structure of Scientific Revolutions. Chicago: University of Chicago Press.

Kuhn, T. (1977) The Essential Tension. Chicago: University of Chicago Press.

Lakatos, I., \& Musgrave, A. (1970) Criticism and the Growth of Knowledge. New York: Cambridge University Press.

Lee, A. (1985) "The Scientific Basis for Conducting Case Studies of Organizations." Proceedings '85 of the Academy of Management.

Lee, A. (1986a) "The Case Study of an Organization as a Scientific Research Strategy." Northeastern University, College of Business Administration, Working Paper 86-25.

Lee, A. (1986b) "Case Studies as Natural Experiments." Presented at the national meeting of the Decision Sciences Institute, Honolulu, Hawaii.

Lee, A. (1987) "A Scientific Methodology for MIS Case Studies." Northeastern University, College of Business Administration, Working Paper 87-28.

Lee, S., Moore, L., \& Taylor, B. (1985) Management Science. Dubuque, Iowa: Brown, 1985

Luckmann, T. (1978a) "Preface." In T. Luckmann, Phenomenology and Sociology: 7-13. New York: Penguin.

Luckmann, T. (1978b) "Philosophy, Social Sciences, and Everyday Life." In T. Luckmann, Phenomenology and Sociology: 217-253. New York: Penguin.

Luckmann, T. (1978) Phenomenology and Sociology. New York: Penguin.

Mintzberg, H. (1979) "Beyond Implementation: An Analysis of the Resistance to Policy Analysis." In K.B. Haley, Operational Research '78. Amsterdam: North Holland. 
Mitchell, T. (1985) "An Evaluation of the Validity of Correlational Research Conducted in Organizations." Academy of Management Review, 10: 192-205.

Nagel, E. (1979) The Structure of Science. Indianapolis: Hacket.

Nagel, E., \& Newman, J. (1960) Godel's Proof. New York: New York University.

Natanson, M. (1963) Philosophy of the Social Sciences. New York: Random House.

Popper, K. (1968a) The Logic of Scientific Discovery. New York: Harper Torchbooks.

Popper, K. (1968b) Conjectures and Refutations: The Growth of Scientific Knowledge. New York: Harper Torchbooks.

Rabinow, R., \& Sullivan, W. (1979) Interpretive Social Science. Berkeley and Los Angeles: University of California Press.

Ratcliffe, J. (1983) "Notions of Validity in Qualitative Research Methodology." Knowledge, 5: 147-167.

Sabatier, P. (1978) "The Acquisition and Utilization of Technical Information by Administrative Agencies." Administrative Science Quarterly, 23: 396-417.

Sanday, P. (1979) "The Ethnographic Paradigm(s)." Administrative Science Quarterly, 24: 527-538.

Schon, D. (1983) The Reflective Practitioner: How Professionals Think in Action. New York: Basic Books.

Schon, D., Drake, W. \& Miller, R. (1984) "Social Experimentation as Reflection-in-Action. Knowledge, 6, 5-36.

Schutz, A. (1973) "Concept and Theory Formation in the Social Sciences." In A. Schutz, Collected papers, Vol. 1: 48-66. The Hague: Martinus Nijhoff.

Shapere, D. (1979) "Notes Toward a Post-Positivistic Interpretation of Science." In P. Achinstein \& S. Barker, The Legacy of Logical Positivism: 115-160. Baltimore: Johns Hopkins.

Simon, H. (1981) The Sciences of the Artificial. Cambridge: M.I.T. Press.

Stone, E. (1978) Research Methods in Organizational Behavior. Glenview, Illinois: Scott, Foresman.

Susman, G., \& Evered, R. (1978) "An Assessment of the Scientific Merits of Action Research." Administrative Science Quarterly, 23 : 582-602. 